\title{
Comparison of Clinical Usefulness of Program-Assisted and Real Ear Measurement-Assisted Hearing Aids Fitting
}

\author{
Young-Soo Chang ${ }^{1}$, Hye Im Jung ${ }^{2}$, and Yang-Sun Cho ${ }^{1}$ \\ ${ }^{I}$ Department of Otorhinolaryngology-Head and Neck Surgery, Samsung Medical Center, Sunkyunkwan University School of Medicine, \\ Seoul; and ${ }^{2}$ Hearing Research Laboratory, Samsung Medical Center, Seoul, Korea
}

\author{
프로그램과 실이 측정을 이용한 보청기 적합의 임상적 유용성의 비교 \\ 장영수 ${ }^{1}$ 정혜임 ${ }^{2} \cdot$ 조양선 ${ }^{1}$ \\ 성균관대학교 의과대학 삼성서울병원 이비인후과학교실, ${ }^{1}$ 삼성서울병원 난청연구실 ${ }^{2}$
}

\author{
Received January 18, 2018 \\ Revised April 12, 2018 \\ Accepted April 25, 2018 \\ Address for correspondence \\ Yang-Sun Cho, MD, PhD \\ Department of Otorhinolaryngology- \\ Head and Neck Surgery, \\ Samsung Medical Center, \\ Sungkyunkwan University \\ School of Medicine, \\ 81 Irwon-ro, Gangnam-gu, \\ Seoul 06351, Korea \\ Tel $+82-2-3410-3578$ \\ Fax $+82-2-3410-3879$ \\ E-mail yscho@skku.edu
}

Background and Objectives The main objectives of this study were to determine the clinical usefulness of the program-assisted and real ear measurement (REM)-assisted fitting of hearing aids.

Subjects and Method Fifteen participants with moderate to moderately severe hearing loss were enrolled in this study. Objective and subjective fitting results were assessed to compare the benefits between the program-assisted fitting (using a software fitting program) and the REM-assisted fitting. Real ear insertion gain (REIG), sound-field audiometry using warble tone, and Korean Hearing in Noise Test (K-HINT) were performed as objective tests. Sound quality rating was performed as a subjective test.

Results In the program fitting, $48.89 \%$ of fitting points failed to come within $\pm 10 \mathrm{~dB}$ of the REIG target. In the REM fitting, however, the percentage of failure significantly decreased to $23.33 \%(p=0.013)$. In K-HINT test, the reception threshold for speech in quiet situation significantly decreased from $50.1 \mathrm{~dB}$ HL with the program fitting to $44.7 \mathrm{~dB}$ HL after the REM fitting $(p<0.001)$. In front noise condition, signal-to-noise ratio improved from $4.53 \mathrm{~dB}$ to $3.50 \mathrm{~dB}$ with the REM fitting without statistical significance $(p=0.099)$. In the sound quality rating, the REM fitting $(4.27 \pm 0.56)$ showed a significantly better sound quality ratings than the program fitting $(3.69 \pm 0.74)(p=0.017)$.

Conclusion The REM fitting showed better results in both subjective and objective measurements than the program fitting. Korean J Otorhinolaryngol-Head Neck Surg 2018;61(12):663-8

Key Words Hearing aids fitting · Korean Hearing in Noise Test · Real ear measurement · Sound quality.

\section{서 론}

보청기 적합(hearing aid fitting)은 환자의 난청 유형이나 중증도 및 개인적 선호도를 고려하여 선택한 보청기의 음향 이득과 출력 음압을 결정하여 환자가 보청기 사용을 통해 최

This is an Open Access article distributed under the terms of the Creative Commons Attribution Non-Commercial License (https://creativecommons.org/licenses/by-nc/4.0) which permits unrestricted non-commercial use, distribution, and reproduction in any medium, provided the original work is properly cited.
적의 이득을 얻을 수 있도록 하는 과정이다. 보청기 적합 이후 에는 보청기의 음향학적 이득을 객관적으로 평가하는 보청기 검증(verification) 과정과 보청기를 착용하면서 일상생활에 서 주관적인 만족도를 평가하는 기능적 확인(validation)을 시행하여 적절한 보청기 적합이 이루어졌는지를 평가한다. 보 청기 사용자는 반복적인 보청기 적합을 통하여 새로운 보청 기에 적응하고 최적의 이득을 얻을 수 있으며 이 과정에 약 6 12주가 소요된다. ${ }^{1)}$ 
실이 측정(real ear measurement, REM)은 보청기 검증의 한 가지 방법으로 보청기 착용 전과 후에 외이도 내에서 측 정한 음압 차이를 비교하여 보청기의 이득을 측정하는 방법 이다. 외이도 내부로 고막 가까이에 실리콘 재질의 probe microphone 관을 삽입하여 각 주파수에서 보청기에 의해 증폭된 음압을 측정한다. 실이삽입이득(real ear insertion gain, REIG) 은 보청기를 착용하지 않았을 때의 실이공명반응(real ear unaided response, REUR)에 비해서 보청기를 착용했을 때 의 실이증폭반응(real ear aided response, REAR)이 얼마나 증가하였는지를 나타내며 이 반응이 목표 이득(target gain) 과 얼마나 차이가 나는지를 평가한다. 검사는 약 5 10분 정 도 소요되는 객관적인 측정 방법으로 보청기를 통해 전달되 는 외이도 내의 음압의 정보를 모니터의 스펙트럼을 통해 실 시간으로 확인할 수 있기 때문에 환자에게 객관적인 자료를 제공할 수 있다는 장점을 가지고 있으며 환자 개개인의 특성 을 반영한 보청기 적합에 유용하다.

개인별 외이도의 특성에 따라 실제 외이도 내에 전달되는 보청기의 출력 음압이 다르기 때문에 개인적 차이를 고려한 정확한 보청기 적합을 위한 실이 측정 시행의 유용성이 보고 되었으나, ${ }^{2-5)}$ 2005년 미국에서 시행한 연구에 따르면 $57 \%$ 의 기관에서 실이 측정 장비를 가지고 있지만 장비 보유 기관 중 $34 \%$ 만 이를 지속적으로 사용하고 있다고 보고하여, 전체적 인 보청기 적합의 과정에서 실이 측정이 실제적으로 시행되는 비율은 약 $19 \%$ 수준임을 보고하였다.) 즉, 실제 보청기 적합 의 과정에서 실이 측정은 낮은 빈도로 시행되고 있고,") 대부 분의 경우에는 보청기 제조사에서 제공하는 프로그램을 이 용한 실이증폭반응 예측치를 기준으로 보청기 적합을 시행 하고 있다.

Aarts와 $\mathrm{Caffee}^{8}$ 는 프로그램에서 제공하는 실이증폭반응 예측치(predicted real ear aided response)와 실이 측정을 통 한 실이증폭반응의 비교 연구를 시행하였다. 연구 결과 실이 측정의 실이증폭반응과 프로그램을 통해 측정되는 실이증폭 반응은 대부분의 주파수에서 차이를 나타냈는데, 그 이유로 프로그램의 예측치는 환자 개인의 특성에 맞춘 것이 아니라 환자군의 평균 값을 이용한 것이기 때문이라고 고찰하였다. Aazh와 Moore ${ }^{3)}$ 는 실이삽입이득의 유용성을 평가하기 위하 여 프로그램의 목표 이득 값과 실이삽입이득 값의 차이가 \pm 10 $\mathrm{dB}$ 이상 차이가 났을 때, 최적 적합에 실패한 것으로 정의했 을 때, 프로그램을 통한 보청기 적합 시에는 $64 \%$ 에서 최적 적 합을 하지 못했지만, 실이 측정을 통하여 목표 이득 값을 재 조정하고 난 후에는 실패율이 $17 \%$ 로 개선되었다.

이와 같이 선행 연구들에서는 프로그램을 이용한 보청기 적합의 문제점을 제시하고 실이 측정의 유용성을 제시하였
으나, 주로 각 주파수별 실이삽입이득 측면에서 비교 분석이 진행되었으며, 보청기 사용자들이 소음 환경과 같은 일상생활 속에서 겪는 청각학적 이득이나 음질에 대한 주관적 선호도 에 대한 연구는 충분히 시행되지 않았다. 이에 본 연구에서는 최근 많이 이용되는 개방형(receiver-in-the-canal, RIC) 보청 기를 착용할 때 프로그램을 이용한 보청기 적합과 실이 측정 을 이용한 보청기 적합의 이득을 실이삽입이득 평가, 소음 환 경에서의 문장 인지능력 및 음질 선호도 평가를 통하여 비교 하여 실이 측정을 이용한 보청기 적합의 유용성을 평가하고 자 하였다.

\section{대상 및 방법}

\section{대 상}

본 연구는 2015년 9 11월에 3차 병원 보청기 클리닉을 내원 한 만 19세 이상의 성인을 대상으로 전향적으로 진행되었다. 대상 기준은 일측 혹은 양측의 청력 역치가 $41 \sim 70 \mathrm{~dB}$ 인 중증 도 및 중고도 감각신경성 난청 환자로서 $50 \%$ 이상의 어음인 지도 점수를 만족하는 환자를 대상으로 하였다. 총 15 명의 대상자를 선정하였고, 대상자의 평균 연령은 $52.4 \pm 14.13$ 세, 분포는 24세부터 67세였다(Table 1). 본 임상시험은 병원 윤 리심의위원회(Institutional Review Board)의 승인을 받아 전 향적으로 진행되었으며 연구 과정에 대한 설명 후 환자 동의 하에 진행되었다(IRB No. 2015-08-025-002).

\section{검사 방법}

\section{보청기}

본 연구에 참여한 검사 대상자는 모두 Phonak 사(Seoul, Korea)에서 출시된 RIC 형태의 보청기(Audeo S Smart V) 를 사용하여 검사를 시행하였다. 제조사에서 제공하는 프로 그램(Phonak Target)을 사용하여 보청기 적합을 시행하였고 이때 목표 이득(target gain)은 NAL-NL1을 활용하였다. 출력 음압에 영향을 미칠 수 있는 소음감소 기능 및 SoundRecover 기능은 소거하였다. SoundRecover 기능은 Phonak 사의 주 파수 압축방식(frequency compression)으로, 중 저주파 영 역의 정보는 보존하고 고주파 영역의 압축을 통하여 고주파 난청 환자가 고주파에 담긴 어음 정보를 청취 가능하도록 돕 는 기능이다.

\section{프로그램 적합 및 실이 적합}

본 연구에서 프로그램 적합은 Phonak Target(Phonak)를 이용하여 연구 대상 보청기를 기본 적합(basic fitting)을 시행 
Table 1. Baseline characteristics

\begin{tabular}{|c|c|c|c|c|c|c|c|c|c|c|c|}
\hline \multirow{2}{*}{$\begin{array}{l}\text { Coding } \\
\text { No. }\end{array}$} & \multirow{2}{*}{ Age } & \multirow{2}{*}{ Gender } & \multirow{2}{*}{$\begin{array}{l}\text { Period of hearing } \\
\text { aid use (months) }\end{array}$} & \multirow{2}{*}{ Laterality } & \multicolumn{6}{|c|}{ Pure tone audiometry of test ear ( $\mathrm{dB}$ ) } & \multirow{2}{*}{$\begin{array}{c}\text { Word recognition } \\
\text { score }\end{array}$} \\
\hline & & & & & 500 & 1000 & 2000 & 3000 & 4000 & 6000 & \\
\hline 1 & 47 & $M$ & 92 & Left & 55 & 65 & 65 & 60 & 55 & 70 & 54 \\
\hline 2 & 61 & M & 79 & Left & 55 & 70 & 75 & 70 & 75 & 75 & 88 \\
\hline 3 & 62 & M & 146 & Right & 40 & 55 & 60 & 65 & 70 & 85 & 38 \\
\hline 4 & 41 & $\mathrm{~F}$ & 158 & Right & 40 & 45 & 55 & 80 & 105 & 90 & 58 \\
\hline 5 & 24 & $\mathrm{~F}$ & 67 & Right & 45 & 65 & 60 & 55 & 60 & 70 & 82 \\
\hline 6 & 58 & $\mathrm{~F}$ & 64 & Right & 50 & 55 & 60 & 60 & 75 & 70 & 90 \\
\hline 7 & 67 & $\mathrm{~F}$ & 55 & Left & 55 & 50 & 60 & 55 & 55 & 70 & 86 \\
\hline 8 & 40 & $M$ & 222 & Left & 55 & 50 & 60 & 65 & 70 & 80 & 75 \\
\hline 9 & 23 & $\mathrm{~F}$ & 157 & Right & 65 & 65 & 65 & 60 & 60 & 85 & 86 \\
\hline 10 & 54 & $F$ & 75 & Right & 55 & 70 & 70 & 65 & 60 & 60 & 76 \\
\hline 11 & 56 & $\mathrm{~F}$ & 13 & Left & 55 & 55 & 55 & 50 & 55 & 55 & 88 \\
\hline 12 & 52 & $F$ & 13 & Left & 45 & 45 & 60 & 65 & 70 & 70 & 88 \\
\hline 13 & 52 & $M$ & 12 & Right & 45 & 45 & 65 & 65 & 65 & 60 & 96 \\
\hline 14 & 67 & $M$ & 12 & Right & 60 & 65 & 65 & 65 & 70 & 65 & 58 \\
\hline 15 & 66 & $\mathrm{~F}$ & 2 & Right & 55 & 55 & 55 & 60 & 60 & 60 & 100 \\
\hline
\end{tabular}

하는 것을 의미한다. 실이 적합은 프로그램 적합을 시행한 후 실이 측정으로 실이삽입이득을 확인하여 목표 이득과의 차 이만큼 이득을 추가로 준 것을 의미한다. 추가해서 나온 최 종 이득 값이 제조사에서 제공하는 소프트웨어에서 줄 수 있 는 최대의 이득 값보다 클 경우 최대로 줄 수 있는 이득까지만 을 주었다. 실이 측정은 Fonix $7000^{\circledR}$ (Frye, Tigard, OR, USA) 을 이용하였다. 보청기를 착용하지 않은 상태에서 실이공명이 득 측정 시 자극음은 $60 \mathrm{~dB} \mathrm{SPL}$ 의 복합음(composite noise) 을 일정한 강도로 제시하였다. 이후 보청기를 착용한 상태에 서 실이공명이득을 측정할 때와 동일한 조건으로 검사를 시 행하여 실이증폭이득 및 실이삽입이득을 측정하였다. 500 , $1000,2000,3000,4000,6000 \mathrm{~Hz}$ 에서 실이 측정을 시행하 였으며 각각의 적합 결과와 실이삽입목표 값의 차이가 $10 \mathrm{~dB}$ $\mathrm{SPL}$ 이상인 경우 최적의 적합에 실패하였다고 평가하였다. ${ }^{3)}$ 프로그램 적합과 실이 적합을 이용한 검사는 연속적으로 진 행되었으며, 환자의 등록 번호와 연결된 무작위 배정표에 의 거하여 프로그램 적합과 실이 적합의 순서를 결정하여 진행 하였다.

\section{보청기 이득의 평가}

각각 프로그램 적합 및 실이 적합이 이루어진 보청기를 착 용한 상태에서 보청기 착용자의 이득을 평가하기 위하여 음 장청력검사, 소음 환경에서의 문장 인지능력, 음질 평가를 시 행하였다.

음장청력검사는 변조 순음(warble tone)을 이용하여 500, $1000,2000,3000,4000,6000 \mathrm{~Hz}$ 대역에서 $5 \mathrm{~dB}$ 수정상승 법으로 청력 역치를 평가하였다.
소음 환경에서의 문장 인지능력을 평가하기 위하여 Korean Hearing In Noise Test(K-HINT) 검사를 이용하였다. HINT 검사는 소음 환경에서 말소리를 알아듣는 정도를 측정하기 위하여 1994년 Nilsson 등 ${ }^{9}$ 에 의하여 어음인지검사(speech reception test)를 변형하여 개발되었다. 이 검사는 간단한 회 화체 문장의 인지수준(reception level)을 소음 유무에 따라 각각 측정하는 방법으로, 정상 범주와 비교가 가능하며, 소음 환경에서 의사소통의 어려움 정도를 평가할 수 있다. 검사는 조용한 상황(quiet)과 정면 소음(front noise) 상황에서 HINT 장비(HINT pro 7.2; Bio-logic ${ }^{\circledR}$ Systems, Natus Medical Inc., Pleasanton, CA, USA)를 이용하여 실시하였다. 검사방 법으로 녹음된 문장을 정면 1미터 거리에서 스피커를 통하 여 들려주었고, 소리 강도는 정답 여부에 따라 결정되었다. 무소음 환경에서 검사는 문장을 인지하는데 무리가 없는 인 지 역치(reception threshold for speech)를 측정하였다. 문 장 소리 강도 $15 \mathrm{~dB}$ 에서 시작하여 정답의 경우 $4 \mathrm{~dB}$ 감소하고, 오답의 경우 $4 \mathrm{~dB}$ 증가하여 다음 문장을 주었으며, 5 번째 문 장부터는 $2 \mathrm{~dB}$ 간격으로 전체 20 문장을 검사하였다. 각 문장 에 포함된 중요 단어들을 정확하게 반복할 경우 정반응으로 평가하였으며, 하나의 중요 단어라도 틀리는 경우 그 문장은 틀린 것으로 기록하였다. 문장 정답률이 $50 \%$ 가 될 때 문장 소리 강도 역치 값으로 평가하였다. 소음 환경에서는 정면에 서 어음 스펙트럼 소음(speech spectrum noise)을 소음 강도 $65 \mathrm{dBA}$ 로 고정하여 제시하였다. 문장 소리 강도는 $65 \mathrm{~dB}$ 의 소리 강도에서부터 무소음 환경과 동일한 방법으로 검사하 였다. 검사 순서에 의한 오류를 줄이기 위해서 모든 문장은 무작위로 선택되었다. 소음 하 환경에서는 연구 대상자가 제 
시되는 검사 문장의 $50 \%$ 를 맞추는 신호대비 잡음비(signal to noise ratio, SNR)로 나타내어 평가하였다. ${ }^{10)}$ 신호대비 잡음 비는 소음 강도 $(65 \mathrm{dBA})$ 와 문장 소리 강도 역치의 $\mathrm{dB}$ 차이를 계산하여 $\mathrm{dB}$ SNR로 표시하였다.

보청기의 음질 평가는 International Telecommunication Union(ITU)의 ITU-T P.800 규격에 근거하여 시행되었다. ${ }^{11)}$ ITU-T는 전화 등의 주관적 객관적 품질 평가 방법에 대한 국 제 규격으로, 주관적 성능 평가는 mean opinion score(MOS) 를 이용하도록 권고하고 있다. 평가 방법은 음향학적으로 분 석이 이루어진 문장 세트를 여러 명의 음성으로 녹음 후 피 험자가 이를 듣고 음질에 대한 주관적 평가를 5점 척도로 정 량화한다. 일반적으로 4점 이상은 고품질로 평가하며 3.5 4 점은 자연스러운 통화 수준, 3 3.5점은 대화는 잘 이루어지 지만 품질 저하를 느낄 수 있는 수준으로 평가한다. 본 연구 에서는 Korean Standard-Sentence Lists-A의 문장을 이용 하여 평가하였다.

\section{통계 분석 방법}

통계 처리는 Windows용 SPSS version 18.0(SPSS Inc., Chicago, IL, USA) 프로그램을 이용하여 분석하였으며 $p^{-}$ value가 0.05 미만인 경우를 통계학적으로 유의한 것으로 정 의하였다. 프로그램 적합과 실이 적합에서 주파수별 실패 케 이스의 비율의 비교 분석을 위해 카이제곱 검정(chi-square test)을 실시하였다.

청력검사 및 소음 하 문장인지도 검사, 음질 평가는 ShapiroWilk 검정을 통해 변수의 정규성 검정을 시행 후 정규성을 만족하는 경우 paired t-test, 정규성을 만족하지 않을 경우 Wilcoxon signed rank test를 시행하였다.

Table 2. The number (percentage) of failure at frequencies

\begin{tabular}{cccc}
\hline Frequency $(\mathrm{Hz})$ & $\mathrm{N}$ & Program fitting $(\%)$ & REM fitting (\%) \\
\hline 500 & 15 & $8(53.33)$ & $1(6.67)$ \\
1000 & 15 & $3(20.00)$ & $2(13.33)$ \\
2000 & 15 & $6(40.00)$ & $6(40.00)$ \\
3000 & 15 & $11(73.33)$ & $6(40.00)$ \\
4000 & 15 & $11(73.33)$ & $4(26.67)$ \\
6000 & 15 & $5(33.33)$ & $2(13.33)$ \\
\hline
\end{tabular}

REM: real ear measurement

\section{결 과}

\section{실이 측정}

총 15 명의 환자에서 프로그램 및 실이 적합의 삽입 이득을 평가하였다. 6 개의 주파수 $500,1000,2000,3000,4000$, $6000 \mathrm{~Hz}$ )에서 각각 프로그램 및 실이 적합 삽입 이득의 실패 를 평가하였다(Table 2). 총 90개의 적합점에서 프로그램 적 합은 $48.89 \%$ 의 실패율을 나타냈으며, 실이 적합은 $23.33 \%$ 의 실패율을 나타냈다. 프로그램 적합과 실이 적합의 실패율은 통계적으로 유의한 차이를 보였다(chi-square test, $p=0.013$ ) (Table 3).

\section{청력검사}

보청기를 착용하지 않았을 때의 4분법 평균 역치는 60.08 $\mathrm{dB}$ HL이었고, 프로그램 적합을 실시하였을 때 $35.92 \mathrm{~dB} \mathrm{HL}$, 실이 적합을 시행하였을 때는 $30.83 \mathrm{~dB} \mathrm{HL}$ 으로 실이 적합에 서 유의하게 낮은 역치를 나타냈다 $(p<0.001$, paired t-test $)$ (Fig. 1). 두 가지 적합 방법에서 주파수별 청력 역치의 차이 는 $1000 \mathrm{~Hz}$ 와 $2000 \mathrm{~Hz}$ 를 제외한 주파수에서 유의한 차이 가 관찰되었다 $(p<0.05)$.

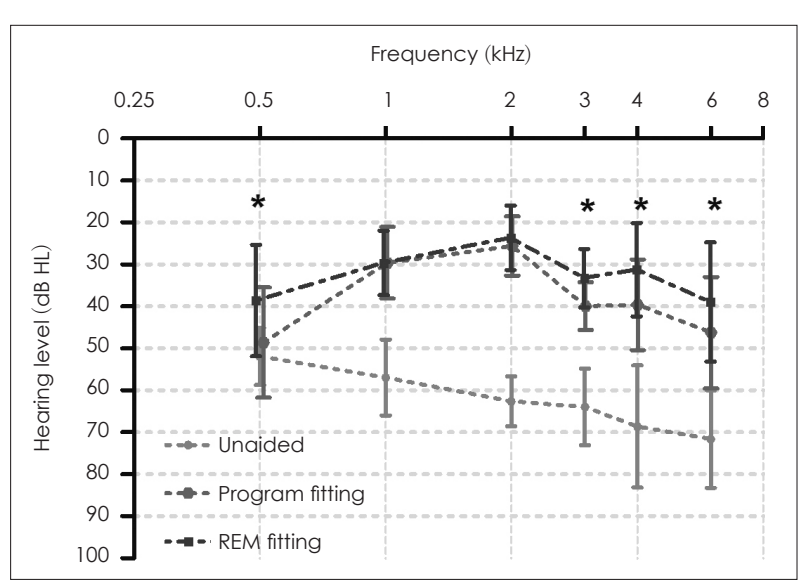

Fig. 1. Comparison of mean and standard deviation (vertical error bars) of sound-field audiometry using warble tone in unaided condition, program fitting, and REM fitting. *statistical significance between program fitting and REM fitting $(2000,3000,4000 \mathrm{~Hz}$ : paired t-test, $500,1000,6000 \mathrm{~Hz}$ : Wilcoxon signed rank test). REM: real ear measurement.

Table 3. Distribution of success and failure for program fitting and REM fitting

\begin{tabular}{lllll} 
& & \multicolumn{2}{c}{ REM fitting } & Total (\%) \\
\cline { 2 - 3 } & & Success & Failure & \\
\hline Program fitting & Success & 40 & 6 & $46(51.11)$ \\
& Failure & 29 & 15 & $44(48.49)$ \\
\hline Total $(\%)$ & & $69(76.67)$ & $21(23.33)$ & \\
\hline
\end{tabular}

*chi-square test. REM: real ear measurement 


\section{소음 하 문장인지도 검사(K-HINT)}

프로그램 적합과 실이 적합 상태의 보청기를 이용하여 시행 한 $\mathrm{K}-\mathrm{HINT}$ 검사의 조용한 환경에서 시행한 문장 인지 시의 청력 역치는 실이 적합에서 유의하게 낮았다 $(p<0.001)$ (Table 4). 정면 소음이 주어진 환경에서 평가한 신호대비 잡음비의 평균(土표준편차)은 프로그램 적합 시 4.53( \pm 3.88$) \mathrm{dB} \mathrm{SNR}$ 이었고 실이 적합 시 $3.50( \pm 3.00) \mathrm{dB} \mathrm{SNR}$ 이었다 $(p=0.099)$.

\section{음질 평가}

총 5 개의 문장에 대하여 프로그램 적합과 실이 적합 이후 의 주관적인 음질 평가를 시행하였다. 문장에 대한 주관적인 음질 평가의 평균( \pm 표준편차)은 프로그램 적합 시에 3.69( \pm $0.74)$, 실이 적합 시에는 4.27( \pm 0.56$)$ 로 실이 적합 시에 유의하 게 우수한 평가를 받았다 $(p=0.017$, paired t-test)(Table 5).

\section{고 찰}

본 연구의 목적은 프로그램 적합과 실이 적합의 차이에 대 해 실이 측정을 이용한 실패율 평가를 통해 객관적 검증을 시 행하고, 추가적으로 소음 환경에서의 문장 인지능력 및 음질 선호도 평가 결과를 비교하여 실이 측정을 이용한 보청기 적 합의 유용성을 평가하고자 하였다. 본 연구에서 객관적 검증 을 위해 실이 삽입 목표 이득과 비교하였을 때 프로그램 적 합은 $48.89 \%$ 의 실패율을 보여서 실이 적합의 실패율 $23.33 \%$ 에 비하여 유의하게 높은 실패율을 나타냈으며, 이는 선행 연구에서와 유사한 양상을 나타냈다.,12) 특이점은 이전 선행 연구에서와 마찬가지로 실이 측정을 시행하면서 이득을 추 가로 더 준 실이 적합에서도 $20 \%$ 내외의 실패율을 나타냈으 며 특히 $2000,3000 \mathrm{~Hz}$ 에서 각각 $40 \%$ 의 적합점에서 실이삽

Table 4. Results of Korean-Hearing in Noise Test

\begin{tabular}{lcc}
\hline & Quiet $(\mathrm{dB} \mathrm{HL})$ & Front noise $(\mathrm{dB}$ SNR) \\
\hline Unaided & $68.42(6.25)$ & $5.54(5.12)$ \\
Program fitting & $50.13(7.20)$ & $4.53(3.88)$ \\
REM fitting & $44.67(5.69)$ & $3.50(3.00)$ \\
p-value* & $<0.001$ & 0.099 \\
\hline
\end{tabular}

Data are mean \pm standard deviation values. *paired t-test between program fitting and REM fitting results. SNR: signal-tonoise ratio, REM: real ear measurement, $\mathrm{HL}$ : hearing level
입이득 $\pm 10 \mathrm{~dB}$ 의 적합에 실패하였으며, 이는 개방형 보청기 를 이용하여 실이 적합을 평가하였던 이전 연구에서와 유사 한 결과를 보였다. ${ }^{12)}$ 그 이유로는 본 연구에서와같이 개방형 보청기를 사용하더라도 일반적으로 $2 \sim 5 \mathrm{kHz}$ 에서 주로 발생 하는 피드백 현상으로 인하여 제조사에서 고주파의 증폭을 일부 제한하고 따라서 목표 이득까지의 적절한 적합이 어려 워지기 때문으로 추정된다. ${ }^{3,12}$

본 연구에서는 K-HINT를 이용하여 소음 하 문장 인지능 력을 평가하여, 실이 적합이 출력 음압의 조절뿐 아니라 실제 환경에서 나타내는 특징을 평가하고자 하였다. 조용한 환경 에서 시행한 문장 인지능력 평가 상 실이 적합 보청기를 사용 할 때 프로그램 적합에 비해 이득을 추가로 주게 되므로 문 장 인지에 대한 청력 역치가 낮아지게 된다. 그러나 소음 감소 기능을 소거한 상태에서 정면에서 소음이 주어지는 환경에서 는 실이 적합을 하더라도 문장 신호와 함께 소음도 크게 증 폭이 되므로 신호대비 잡음비를 호전시키지는 못한 것으로 추정된다. 특히 이러한 특징은 연구 대상 환자 중 보청기 사 용 기간이 12 개월 안팎으로 비교적 짧은 환자들에서 관찰되 었으며, 이는 보청기를 통하여 소음을 듣는 것이 익숙하지 않 고 소음 제거 기능이 제거된 상태에서 $\mathrm{K}-\mathrm{HINT}$ 검사가 시행 되어 두 가지 적합 방식 모두에서 적절한 문장 인지가 어려웠 을 가능성이 높을 것으로 추정된다. 또한 본 연구에서는 환자 의 연령대와 보청기 사용 기간이 다양하였고 대상 피험자가 작아 통계적 유의성 판별이 어려웠을 것으로 사료되며 후속 연구를 통하여 실이 적합과 소음 환경에서의 언어 인지능력 의 연관성을 보청기의 사용 기간, 연령에 따라 분석하여 실이 적합의 임상적 유용성을 평가하는 것이 필요하다.

본 연구에서 음장 청력검사를 시행했을 때 프로그램 적합 을 시행한 경우와 실이 적합을 시행한 경우 $1000,2000 \mathrm{kHz}$ 에서는 역치의 차이가 통계적으로 유의하지 않았다. 이 결과 는 선행 연구에서 프로그램 적합이 1000 3000 Hz의 중간 주파수에서 낮은 실이 측정 실패율을 나타내며, 2 $2 \mathrm{cc}$ 접합기 를 이용한 접합기 측정(coupler measurement)과 비교할 때 도 과예측(overestimation)의 비율이 낮았다는 보고 ${ }^{13}$ 와 유 사한 결과를 보인다. 특이점은 Campos 등릐 선행 연구와 다르게 $500 \mathrm{~Hz}$ 에서 실이 적합의 음장 청력검사 상 청력 역 치가 유의하게 낮았다. 일반적으로 프로그램 적합은 NAL

Table 5. Results of Sound Quality Test

\begin{tabular}{lcccccc}
\hline & Sentence $^{*}$ & Sentence $2^{\dagger}$ & Sentence $3^{*}$ & Sentence $^{\dagger}$ & Sentence $^{*}$ & Average $^{\dagger}$ \\
\hline Program fitting & $3.73(0.80)$ & $3.13(1.36)$ & $3.53(1.13)$ & $4.07(0.88)$ & $4.00(1.00)$ & $3.69(0.74)$ \\
REM fitting & $4.27(0.70)$ & $4.00(1.07)$ & $4.27(0.70)$ & $4.40(0.63)$ & $4.40(0.91)$ & $4.27(0.56)$ \\
p-value & 0.021 & 0.054 & 0.076 & 0.238 & 0.076 & 0.017 \\
\hline
\end{tabular}

Data are mean \pm standard deviation values. *wilcoxon signed rank test, tpaired t-test. REM: real ear measurement 
적합 알고리즘을 기반으로 작동하기 때문에 저주파의 과도 한 증폭으로 인한 상향 차폐를 막고자 저주파 영역은 적게 증 폭시키나, 실이 적합 시에는 목표치를 설정하고 추가적인 보 청기 이득을 줄 수 있기 때문에 저주파수에서도 유의한 역치 차이가 관찰되었을 가능성이 있다.

본 연구는 동일 보청기를 사용하여 동일 시점에서 각기 다 른 적합 방식을 이용하여 음질 평가를 시행하였다. 음질 평가 시 실이 적합을 시행한 후 음질에 대한 평가가 의미 있게 호전 되었으며 $\mathrm{MOS}$ 평가에서 4.27( \pm 0.56$)$ 을 나타내 실이 적합이 이루어진 보청기 사용 시 음질이 우수하다고 평가하였다. 이 는 실이 적합을 통하여 청력 역치의 호전뿐만 아니라 외이도 에 도달한 음압이 종합되어 주관적으로 인지하는 음질 역시 의미 있게 향상시킬 수 있음을 확인한 것으로 적절한 적합 방식의 선택을 통하여 동일한 보청기에서 주관적인 음질을 개선할 수 있음을 확인하였다.

본 연구의 한계점은 1) 연구에 참여한 피험자가 총 15 명으 로 표본의 크기가 작으며, 2) 환자의 청력 수준은 4분법을 기 준으로 중등도 및 중고도 난청의 환자들을 대상으로 하였으 나 다양한 연령대의 환자가 참여하였고 주파수 별 청력 역치 의 차이가 있어 이러한 특징들이 교란 변수로 작용하였을 가 능성을 배제할 수 없다. 그러나 모든 환자에서 동일한 보청기 를 이용하여 연구가 시행하였기 때문에 보청기에 따른 차이 점을 배제할 수 있었으며, 소음 환경에서의 분석 및 음질 평 가를 통하여 실이 적합의 주관적 유용성을 평가한 데 본 연 구의 의의가 있다고 생각한다.

본 연구를 통하여 실이 적합은 프로그램 적합에 비하여 높은 실이 삽입이득 성공률과 높은 음질 선호도를 나타내어 그 임상적 유용성이 확인되었다. 따라서 실제 임상에서 번거 로움으로 인하여 프로그램 적합만으로 보청기 적합을 마치 는 것보다는 실이 적합을 좀 더 적극적으로 시행함으로써 좀
더 효율적인 적합을 시행할 수 있을 것이다. 그러나 소음 환경 에서의 어음인지는 유의하게 개선되지 않아 다양한 방법을 통한 소음 환경에서의 임상적 이득 증가에 대한 추가적인 연 구가 필요할 것으로 사료된다.

\section{REFERENCES}

1) Gatehouse $S$. The time course and magnitude of perceptual acclimatization to frequency responses: evidence from monaural fitting of hearing aids. J Acoust Soc Am 1992;92(3):1258-68.

2) Campos PD, Mondelli MF, Ferrari DV. Comparison: real and simulated ear insertion gain. Braz J Otorhinolaryngol 2011;77(5):555-8.

3) Aazh H, Moore BC. The value of routine real ear measurement of the gain of digital hearing aids. J Am Acad Audiol 2007;18(8):653-64.

4) Kuk F, Ludvigsen C. Verifying the output of digital nonlinear hearing instruments. Hear Rev 1999;6(11):35-6.

5) Abrams HB, Chisolm TH, McManus M, McArdle R. Initial-fit approach versus verified prescription: comparing self-perceived hearing aid benefit. J Am Acad Audiol 2012;23(10):768-78.

6) Kirkwood DH. Survey: dispensers fitted more hearing aids in 2005 at higher prices. Hear J 2006;59(4):40.

7) Mueller HG, Picou EM. Survey examines popularity of real-ear probemicrophone measures. Hear J 2010;63(5):27-8.

8) Aarts NL, Caffee CS. Manufacturer predicted and measured REAR values in adult hearing aid fitting: accuracy and clinical usefulness. Int J Audiol 2005;44(5):293-301.

9) Nilsson M, Soli SD, Sullivan JA. Development of the hearing in noise test for the measurement of speech reception thresholds in quiet and in noise. J Acoust Soc Am 1994;95(2):1085-99.

10) Moon SK, Mun HA, Jung HK, Soli SD, Lee JH, Park K. Development of sentences for Korean hearing in noise test (KHINT). Korean J Otorhinolaryngol-Head Neck Surg 2005;48(6):724-8.

11) International Telcommunication Union. Methods for objective and subjective assessment of quality. [online] 1996 Aug [cited 2018 Jan 18]. Available from: file:///C:/Users/Administrator/Downloads/T-RECP.800-199608-I!!PDF-E\%20(1).pdf.

12) Aazh H, Moore BC, Prasher D. The accuracy of matching target insertion gains with open-fit hearing aids. Am J Audiol 2012;21(2): $175-80$.

13) Hawkins DB, Cook JA. Hearing aid software predictive gain values: how accurate are they? Hear J 2003;56(7):26-8. 